Revista Verde de Agroecologia e Desenvolvimento Sustentável

http://www.gvaa.com.br/revista/index.php/RVADS

ARTIGO CIENTÍFICO

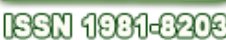

DOI: http://dx.doi.org/10.18378/rvads.v10i4.3793

\title{
Elaboração e caracterização físico-química e microbiológica da farinha da palma (Opuntia fícusindica Mill) em diferentes temperaturas
}

\section{Preparation and physical chemistry and microbiological characterization of flour palm ( Opuntia fícusindica Mill ) at different temperatures}

\author{
Danielle de S. Severo ${ }^{*}$, Alfredina dos S. Araújo ${ }^{2}$,José N. V. Deodato ${ }^{3}$, César C. M. da Silva ${ }^{4}$, Gilcean S. Alves ${ }^{5}$
}

Resumo: A Palma forrageira (Opuntia fícusindica Mill) é uma cactácea originária do México, porém bastante cultivada na região semiárida do nordeste. Na alimentação humana, geralmente, são usados em preparações culinárias os brotos de palma, os frutos in natura ou processados. Uma das maneiras de diversificar o uso da palma forrageira seriam a secagem e sua transformação em farinhas para incorporação em diversos produtos. Desta forma o objetivo deste trabalho foi avaliar a qualidade físico-química e microbiológica da farinha. As amostras foram coletadas na zona rural e transportadas para o laboratório do Centro Vocacional e Tecnológico /UFCG - Campus Pombal - PB, as mesmas foram desidratadas até a total retirada da umidade em estufa de circulação de ar nas seguintes temperaturas: 70,80 e $90{ }^{\circ} \mathrm{C}$, posteriormente passaram por um liquidificador industrial, em seguida por um moinho de facas para a obtenção da farinha. Após a obtenção foram realizadas as análises microbiológicas e analises físico-químicas. O emprego na alimentação humana, a palma forrageira é um grande potencial produtivo do Semiárido com alternativas sustentadas de desenvolvimento.

Palavras-chaves: Qualidade, Cactácea, Microbiologia, Farinha.

Abstract: The Spineless cactus ( Opuntia fícusindica Mill ) is a cactaceous originally from Mexico, but rather grown in semiarid region of the northeast. For human consumption, generally, they are used in culinary preparations the palm shoots, os frutos in natura ou processados. One way to diversify the use of cactus would be drying and processing into meal for incorporation into various products. Thus the aim of this study was to evaluate the physical - chemical and microbiological quality of the flour. The samples were collected in the countryside and transported to the laboratory and Technological Vocational Center / UFCG - Campus Pombal - PB, they have been dewatered to the full withdrawal of moisture in air circulating oven at the following temperatures: 70,80 and $90^{\circ} \mathrm{C}$, subsequently passed through an industrial blender, then by a slicer to obtain the flour. After obtaining it was conducted microbiological analyzes and physicochemical analysis. Employment in food, the cactus is a great productive potential with the Semi-Arid alternatives sustained development.

Key words: Quality, cactaceous Microbiology, flour.

\footnotetext{
*Autor para correspondência

Recebido para publicação em 14/09/2015; aprovado em 10/11/2015

${ }^{1}$ Graduanda, UFCG, Pombal; (83) 99611-6871, danni_severo@hotmail.com.

${ }^{2}$ Doutora, UFCG, alfredina@ccta.ufcg.edu.br

${ }^{3}$ Mestre, UFCG, jnvdeodato@hotmail.com.

${ }^{4}$ Graduando, UFCG, cesaralimentos@gmail.com

${ }^{5}$ Doutor, IFPB, biopb@hotmail.com
} 


\section{INTRODUÇÃO}

A palma (Opuntia e Nopalea) é uma cultura originária do México, sendo atualmente cultivada em todo o mundo. Provavelmente foi introduzida no país durante o período de colonização para a produção da cochonilha do carmim. Em 1893, Barbosa Rodrigues recomendou o uso de Opuntia como forrageira para alimentação do gado nas épocas de seca (Menezes et al., 2005).

A palma forrageira é a opção de cultura xerófila com maior potencial de exploração no Nordeste, constituindo-se em importante recurso forrageiro nos períodos de estiagens, devido ao seu elevado potencial de produção de fitomassa nas condições do Semiárido. Destaca-se por ser cultura de elevado valor nutritivo, rústica, resistente à seca, com elevada eficiência de uso de água e amplamente incorporada ao processo produtivo da região (Guimarães Filho et al., 1995; Araújo Filho, 1977).

A maior área de palma forrageira no Nordeste se concentra no agreste e sertão dos estados de Alagoas e Pernambuco. A Palma está presente em todos os continentes com diversas finalidades podendo ser usada na alimentação de ruminantes, na alimentação humana, na produção de medicamentos, cosméticos e corantes, na conservação e recuperação de solos, produção de biogás, cercas vivas, paisagismo, além de uma infinidade de usos. É a planta mais explorada e distribuída nas zonas áridas e semi-áridas do mundo, contudo sua real dimensão produtiva ainda não foi plenamente conhecida no Nordeste. (LEITE, 2006).

A grande diversidade de usos e aplicações da palma forrageira revela a versatilidade dessa espécie vegetal, que apesar de ser cultivada no semi-árido paraibano para alimentação animal, não tem sua potencialidade explorada plenamente. Em consequência, vêm sendo desperdiçadas excelentes oportunidades para melhoria dos índices sociais e econômicos desse espaço geográfico, mediante a geração de postos de trabalho, renda, oferta de alimentos e preservação ambiental (CHIACHIO, 2006). São utilizadas na alimentação humana, como preparações culinárias, os brotos da palma ou raquetes jovens, denominados de verduras e o fruto da palma, in natura ou processado (REINOLDS \& ARIAS, 2004).

Os cladódios ou raquetes da palma e os frutos são frequentemente consumidos frescos ou processados na América Latina, sendo que somente os frutos frescos são mais difundidos no mercado Europeu e Norte-Americano (FEUGANG et al., 2006). No Brasil várias receitas de pratos com sabores regionais vêm sendo desenvolvidas por Guedes (2002) e por Guedes et al. (2004).

A secagem é uma operação unitária de retirada de água de um produto por evaporação ou sublimação, mediante aplicação de calor sob condições controladas. A secagem tem como finalidade conservar alimentos através da diminuição da atividade de água do mesmo. Nos últimos 50 anos, tanto a ciência quanto a tecnologia empenharam-se no sentido de aprimorar novos sistemas na área de preservação de alimentos, e esses esforços tornaram viável a desidratação de enorme variedade de produtos para fins comerciais. (KAJIYAMA; PARK, 2008).

O melhoramento da qualidade da farinha representa um acréscimo na qualidade do produto, uma oportunidade para se agregar valor ao mesmo (SMANHOTTO, 2006).
No Brasil a diferenciação para cada farinha e sua especialidade, não tem tal relevância, portanto a otimização das farinhas é de grande importância, para que assim cada tipo de farinha atenda as exigências dos determinados produtos finais (GUTKOSKI; ANTUNES, 1999).

Uma alternativa que vem ganhando corpo desde o início da década de 1970 consiste no aproveitamento de resíduos (principalmente cascas e sementes), ou seja, o processo de fabricação de farinhas a partir de certas frutas como matéria-prima para a produção de alguns alimentos perfeitamente possíveis de serem incluídas na alimentação humana, como as barras de cereais (OLIVEIRA et al., 2002; VIDIGAL; VASQUES; MAGALHÃES, 2006). Portanto o objetivo desse trabalho foi produzir farinha de palma, em estufa de circulação de ar, nas temperaturas de 70,80 e $90{ }^{\circ} \mathrm{C}$, e de estudar suas características microbiológicas e físicoquímica.

\section{MATERIAL E MÉTODOS}

As folhas da palma foram coletadas na zona rural do município de Pombal e transportadas para o laboratório do Centro Vocacional e Tecnológico - UFCG - Pombal - PB, as mesmas foram inicialmente trituradas em um liquidificador do tipo industrial e em seguida desidratadas até a total retirada da umidade em estufa de circulação de ar nas seguintes temperaturas (tratamentos): 70, 80 e $90{ }^{\circ} \mathrm{C}$. Após a secagem, as palmas foram moídas em moinho de facas com 4 lamina de aço inoxidável.

Ao final do processo obteve-se uma farinha fina de coloração amarelada e odor característico que foi acondicionada em sacos plásticos polipropileno estilizados com capacidade de $250 \mathrm{~g}$, vedados, etiquetados e mantidos em temperatura controlada a $4^{\circ} \mathrm{C}$. Todos os equipamentos utilizados foram esterilizados para que não houvesse qualquer tipo de contaminação. Foram retiradas amostras para análises microbiológicas com três repetições.

Após a obtenção da farinha as amostras P70, P80 e P90 foram realizadas as seguintes avaliações da qualidade microbiológica, seguindo a Resolução - RDC n ${ }^{\circ} 12$, de 2001, que define o Regulamento Técnico para os padrões microbiológicos para alimentos (BRASIL, 2001). Foram efetuadas as análises de Coliformes à $35^{\circ} \mathrm{C}$ e à $45^{\circ} \mathrm{C}$, Contagem Total de Mesofilo (C.T.M), Psicotrópicos, Staphylococcus aureus, Bolores e Levedura e Salmonella sp/25g.

Posteriormente foram realizadas as seguintes análises físico-químicas: Proteínas (\%), lipídeos (\%), Cinzas (\%) e umidade $(\%)$. Os teores de proteínas foram determinados através do método Kjedahl, descrito pelo Instituto Adolfo Lutz (2008) e os resultados encontrados estão expressos em porcentagem $(\mathrm{p} / \mathrm{p})$, Para a análise de lipídios foi determinado através do aparelho extrator de Soxhlet, seguindo o método descrito 033/IV do Instituto Adolf Lutz (2008), a umidade foi determinada pelo método gravimétrico que se baseia na perda de peso das amostras submetidas a aquecimento à temperatura de $105^{\circ} \mathrm{C}$, em estufa de secagem, até peso constante, e cinzas realizou-se utilizando o método gravimétrico, fundamentado na calcinação da matéria orgânica em forno mufla à temperatura de $550^{\circ} \mathrm{C}$ até que ocorra a combustão total da matéria orgânica e foram determinadas segundo o método 
018/IV do Instituto Adolf Lutz (2008) e os resultados foram expressos em porcentagem (p/p).

\section{RESULTADOS E DISCUSSÃO}

A partir dos resultados obtidos na análise microbiológica encontradas nas farinhas da palma em diferentes temperaturas observou-se na Tabela 1 que coliformes a $45^{\circ} \mathrm{C}$, Staphylococcus coagulase positiva e Salmonella sp estão ausentes, indicando que as farinhas elaboradas não apresentaram condições insatisfatórias na produção e/ou manipulação do alimento tornando-se própria para o consumo humano.

$\mathrm{Na}$ análise de Bacillus Cereus houve apenas presença nas amostra de $\mathrm{P} 70^{\circ} \mathrm{C}$, as demais foram ausente, entretanto todas as amostras se encontram dentro dos padrões estabelecido legislação vigente que é de 3 x $10^{3} \mathrm{UFC} / \mathrm{g}$. bactéria geralmente encontrada no solo e nos reservatórios naturais e, por essa razão, frequentemente contamina vegetais, cereais e tubérculos (GHELARDI et al., 2002). A contaminação de alimentos por $B$. cereus constitui não somente uma importante causa de deterioração, mas também está associada à ocorrência de dois tipos de síndrome, devidos à ingestão de alimentos contaminados com cepas patogênicas produtoras de toxinas, uma emética e outra diarréica (MINNAARD et al., 2001; AGATA et al., 2002; MCELROY et al., 2000; TSEN et al., 2000). A toxina do tipo emético é pré-formada no alimento, enquanto que a do tipo diarréico é, muito possivelmente, produzida no trato intestinal, sendo os fatores de virulência ainda não completamente caracterizados (MINNAARD et al., 2001; GHELARDI et al., 2002; GRANUM et al., 1994).

Em relação a pesquisa de bactéria aeróbias mesófilas, $\mathrm{O}$ Ministério da Saúde, (BRASIL, 1997) não determina limites de tolerância para contagem padrão em farinhas, amidos, féculas e fubás, contudo, LEITÃO e colaboradores (1988) consideram admissível valores máximos entre $10^{4}$ e $10^{6}$ UFC $\mathrm{g}^{-1}$. Seguindo esse critério, pode evidencia-se a boa condição higiênica do produto, uma vez que a contagem máxima de bactérias mesófilas não ultrapassou $10^{3}$ UFC g-1 em nenhuma das amostras analisadas. Em relação a bolores e levedura todas as amostras apresentaram contaminação dentro dos limites estabelecidos.

Tabela 1-Resultados das medias microbiológicas das farinhas de palma submetidas a diferente temperatura de secagem.

\begin{tabular}{ccccccc}
\hline & \multicolumn{5}{c}{ Parâmetros Microbiológicos } \\
\cline { 2 - 7 } Amostras & $\begin{array}{c}\text { Coliformes a } \\
45^{\circ} \mathrm{C}(\mathrm{NMP} / \mathrm{g})\end{array}$ & $\begin{array}{c}\text { Sthapylococcus } \\
\text { Coagulase } \\
\text { positiva (UFC/g) }\end{array}$ & $\begin{array}{c}\text { Bacillus } \\
\text { Cereus } \\
(\mathrm{NMP} / \mathrm{g})\end{array}$ & $\begin{array}{c}\text { Bactérias } \\
\text { Aeróbias } \\
\text { Mesófilas } \\
(\mathrm{NMP} / \mathrm{g})\end{array}$ & $\begin{array}{c}\text { Contagem } \\
\text { de Bolores e } \\
\text { Leveduras } \\
(\mathrm{UFC} / \mathrm{g})\end{array}$ & $\begin{array}{c}\text { Salmonella spp } \\
1,39 \times 10^{2}\end{array}$ \\
\hline $\mathrm{P} 70^{\circ} \mathrm{C}$ & Ausente & Ausente & $6,8 \times 10^{2}$ & $1,98 \times 10^{2}$ & Ausente \\
$\mathrm{P} 80^{\circ} \mathrm{C}$ & Ausente & Ausente & Ausente & $3,82 \times 10^{2}$ & $2,45 \times 10^{2}$ & Ausente \\
$\mathrm{P} 90^{\circ} \mathrm{C}$ & Ausente & Ausente & Ausente & $7,00 \times 10^{2}$ & $5,00 \times 10^{2}$ & Ausente \\
\hline
\end{tabular}

(NMP/g) número mais provável por grama; (UFC/g) unidade formadora de colônia por grama

De acordo com os resultados descritos na Tabela 2 podemos observar que quando comparamos as farinhas do Facheiro com os mesmos tratamentos, analisadas por (DEODATO, 2012) com a farinha da Palma observou-se que alguns resultados estabelecem relação, como o percentual de proteínas: Facheiro80 (1,15\%) e $\mathrm{P} 80^{\circ} \mathrm{C}(1,39 \%)$, lipídeos:
Facheiro90 $(9,0 \%)$ e $\mathrm{P} 90^{\circ} \mathrm{C}(10,15 \%)$, porém a quantidade de cinzas: Facheiro70 $(22,86 \%), \mathrm{P} 70^{\circ} \mathrm{C}(12,30 \%)$ e a umidade: Facheiro70 $(8,1 \%)$ e $\mathrm{P} 70^{\circ} \mathrm{C}(3,97 \%)$ observou-se que são mais distintos, apesar de ambas serem cactáceas essa diferença deve-se a variação das espécies.

Tabela 2-Resultados das medias microbiológicas das farinhas de palma submetidas a diferente temperatura de secagem.

\begin{tabular}{ccccc}
\multirow{2}{*}{ Amostras } & \multicolumn{3}{c}{} \\
\cline { 2 - 5 } & Cinzas (\%) & Umidade (\%) & Proteínas (\%) & Lipídeos $(\%)$ \\
\hline $\mathrm{P} 70^{\circ} \mathrm{C}$ & 12,30 & 8,1 & 1,85 & 10,17 \\
$\mathrm{P} 80^{\circ} \mathrm{C}$ & 12,16 & 5,75 & 1,39 & 7,60 \\
$\mathrm{P} 90^{\circ} \mathrm{C}$ & 12,76 & 4,85 & 1,77 & 10,15 \\
Ffacheiro70 & 22,86 & 3,97 & 1,10 & 12,00 \\
Ffacheiro80 & 23,67 & 2,79 & 1,15 & 10,00 \\
Ffacheiro90 & 20,73 & 4,51 & 0,70 & 9,00 \\
\hline
\end{tabular}

\section{CONCLUSÕES}

As amostras de farinha de Palma forrageira (Opuntia fícusindica Mill) apresentaram contagens microbianas dentro dos padrões estabelecidos pela legislação vigente, revelando que as mesmas não representam riscos à saúde do consumidor e não apresentaram problemas de produção, em relação à extração da farinha de trigo e de estocagem do produto. $\mathrm{O}$ emprego na alimentação humana, a palma forrageira é um grande potencial produtivo do Semiárido com alternativas sustentadas de desenvolvimento.

\section{REFERÊNCIAS BIBLIOGRÁFICAS}

BRASIL. Portaria SVS n. 451 de 19 de setembro de 1997. Aprova o Regulamento Técnico Princípios Gerais para o Estabelecimento de Critérios e Padrões Microbiológicos para Alimentos e seus anexos. Diário Oficial [da] 
República Federativa do Brasil, Poder Executivo, Brasília, DF, 22 de setembro de 1997. Seção 121005.

CHIACCHIO, F.B.; MESQUITA, A. S.; SANTOS, J.R. Palma forrageira: uma oportunidade econômica ainda desperdiçada para o semiárido baiano. Bahia Agríc., v.7, n.3, nov. 2006.

DEODATO, J.N.V. PRODUÇÃO DE FARINHA Cereus squamosus (FACHEIRO) E UTILIZAÇÃO COMO ADITIVO EM BISCOITOS TIPOS COOKIES E BARRAS DE CEREAIS. Monografia de Conclusão de Curso de Engenharia de Alimentos, Universidade Federal de Campina Grande UFCG - Câmpus - Pombal - PB, 2012.

FEUGANG, J.M.; KONARSKI, P.; ZOU, D.; STINTZING; F.C.Z., CHANGPING. Nutritional and medicinal use of Cactus pear (Opuntia spp.) cladodes and fruits. Frontiers in Bioscience 11, 2574-2589, September 1, 2006.

GUEDES, Claudet Coelho et al. Broto de palma - sabor e nutrição: livro de receitas. Recife: SEBRAE PE / FAEPE, 2004. 48p

GUEDES, Claudet Coelho. Culinária com broto de palma. João Pessoa: Universitária, 2002. 53p.

GUIMARÃES FILHO, C,; SOARES, J.G.G.; RICHÉ, G. R. Sistema caatinga - buffel - leucena para produção de bovinos no semiárido. Petrolina, PE: EMBRAPA CPATSA, 39 p., 1995.

GUTKOSKI, L.C., ANTUNES, E., ROMAN, I.T. Avaliação do grau de extração de farinhas de trigo e de milho em moinho tipo colonial. Boletim Ceppa, Curitiba, v.17, n.2, p.153-166, 1999.
KAJIYAMA, T.; PARK, K. J. Influência da umidade inicial da alimentação no tempo de secagem em secador atomizador. Revista Brasileira de Produtos Agroindustriais, v.10, n.1, p.1-8, 2008.

LEITE, M.L.V. Palma Forrageira (Opuntia fícus indica e Nopalea cochenilifera.) Universidade Federal da Paraíba - UFPB, Centro de Ciências Agrárias - CCA,Grupo de Pesquisa Lavoura Xerófila - GPLX, Areia:Jul,2006.

LEITÃO, M.F.F. et al. Tratado de microbiologia. São Paulo : Mamoli, 1988. V.1, 185p.

MENEZES, R. S. C.; SIMÕES, D. A.; SAMPAIO, E. V. S. B. A palma no Nordeste do Brasil - Conhecimento atual e novas perspectivas de uso. Recife: Ed. Universitária da UFRPE, 2005, v. único, p. 44. 2005.

MINNAARD J, HUMEN M, PÉREZ PF. Effect of Bacillus cereus Exocellular Factors on Human Intestinal Epithelial Cells. J Food Protec 2001; 64(10): 1535-41.

REINOLDS, Stephen G.; ARIAS, Enrique. General background on opuntia. Disponível em: http://www.fao.org/DOCREP/005/2808E/y2808e04.htm

SMANHOTTO, A. et al. Características físicas e fisiológicas na qualidade industrial de cultivares e linhagens de trigo e triticale. Campina grande, 2006.

VIDIGAL, F. C.; VARQUES, A. C. J.; MAGALHÃES, B. M. Análise sensorial de biscoitos elaborados com farinhas de maçã e da casca do maracujá. Nutrição em Pauta, set./out. 2006. 